\title{
BANCO DE DADOS GEORREFERENCIADOS PARA AVALIAÇÃO DE RECURSOS MINERAIS NA SUB-BACIA DO RIACHO MALHADA DE PEDRA, CURAÇÁ - BA
}

Diêgo Pereira Costa; Washington de Jesus Sant'anna da Franca Rocha²;

1. Bolsista PIBIC/CNPq, Graduando em Geografia, Universidade Estadual de Feira de Santana, e-mail: costapdiego@gmail.com

2. Orientador, Departamento de Exatas, Universidade Estadual de Feira de Santana, email: francarocha@gmail.com

PALAVRAS-CHAVE: Espectrorradiometria; SIG; Minerais.

\section{INTRODUÇÃO}

Os Sistema de Informações Georreferenciadas (SIG) são comumente conhecidos como um conjunto de ferramentas auxiliares e necessárias para análises espaciais. Tem como uma de suas funcionalidades, a integração de dados devidamente referenciados, para gerar uma nova informação e para auxiliar na tomada de decisão (SILVA, 1999).

Os SIG vêm apresentando um resultado significativo para a pesquisa mineral. Os variados tipos de dados textuais, numéricos, vetoriais e raster podem ser integrados em um Banco de Dados e gerar informações precisas quanto a prospecção, gestão, logística, e outros, para as diversas instituições público/privadas de exploração mineral (SILVA, 1999; TORRES, 2007).

É nesta perspectiva que a presente proposta de trabalho objetivou a elaboração de um Sistema de Informações Georreferenciadas, contendo diferentes tipos de dados, com relação a diferentes atributos de interesse da pesquisa mineral para cobre na Subbacia do Riacho Malhada de Pedra.

Para além da organização e padronização dos dados pré-existentes, objetivou-se também a coleta de assinaturas espectrais dos diferentes tipos de rocha, minerais e solos. De acordo com Alba (2007) a espectrorradiometria estuda os espectros derivados da interação da energia eletromagnética com os objetos radiantes, no caso a reflectância espectral, viabilizando sua utilização na identificação de minerais.

Vale ressaltar que este trabalho expressa os resultados de apenas três meses de bolsa, visto que, o orientador se afastou para pós-doutorado e o regulamento do PIBIC/CNPq não permite a substituição do orientador, prejudicando o andamento deste trabalho.

\section{MATERIAL E MÉTODOS}

Para uma melhor organização e entendimento o presente trabalho foi dividido em duas etapas essenciais ao cumprimento dos objetivos, sendo estas explanadas abaixo:

$1^{\text {a }}$ ETAPA - Trabalho de campo e Coleta de assinaturas espectrais: Versou em realizar medidas Espectrorradiométricas em campo e no Laboratório de Espectrorradiometria LABESPECTRO, que conta com dois Espectrorradiômetros ASD FieldSpec, que abrangem o intervalo de 350 a 2500 nanometros e do software TSG. Nesta etapa foram processadas e caracterizadas as curvas espectrais obtidas a partir das amostras de rochas coletadas em campo.

$3^{\text {a }}$ ETAPA: Elaboração do Banco de Dados Georreferenciados: O desenvolvimento deste banco de dados proposto consistiu em três procedimentos fundamentais i) levantamento dos dados ii) definição dos formatos de dados a ser seguido iii) adequação dos arquivos de saída à proposta do projeto de estudo do pesquisador sênior: 


\section{RESULTADOS \\ BANCO DE DADOS:}

De acordo com Teixeira et. Al. (2010), os depósitos máficos e ultramáficos de Curaçá foram/são objetos de estudo de diferentes pesquisadores. A sub-bacia do riacho malhada de pedras possui seis unidades geológicas: Acaua, Acaua-Juete, Depositos aluvionares e de terraços, Gnaisse bangue, Macururé e Vale do Curaçá (FIGURA 1).

Esta grande variação de unidades geológicas oferta uma litologia muito variada, com: calcilutitos e metapelitos na unidade Acaua; calcarenitos e calcilutitos na unidade Acaua-Juete; anfibolitos, gnaisses, metapiroxenitos e serpentinitos na unidade Gnaisse bangue; gabronoritos, noritos e piroxenitos na unidade Vale do Curaçá; micaxistos, mármores e quartzitos na unidade Macururé e; areias e argilas nos depósitos aluvionares e de terraços.

No contexto geomorfológico, a sub-bacia do riacho malhada de pedras insere-se em duas unidades: uma região de acumulação no baixo curso do rio e nas bordas do rio são Francisco e quase sua totalidade na unidade dos pedimentos funcionais ou retocados por drenagem incipiente. As altitudes variam de $346 \mathrm{~m}$ à $490 \mathrm{~m}$, com uma amplitude de $144 \mathrm{~m}$. As declividades são pouco marcantes, com maiores unidades de área em declives de 0 à $6 \%$.

De acordo com Ab'Saber (2003) esta região nordeste da Bahia encontra-se em condições climáticas de semiaridez, com temperaturas médias anuais dos $24^{\circ} \mathrm{e}$ pluviosidade anual abaixo dos 400mm (SEI,1999). Característica essa que reduz os processos intempéricos e produz solos rasos e arenosos. Cambissolos, Luvissolos, Nessolos, Planossolos e Vertissolos, são solos típicos do semiárido brasileiro. São marcados pelo baixo grau de intemperismo, possuem, em maioria, grande fertilidade natural e são susceptíveis aos processos de degradação ambiental.
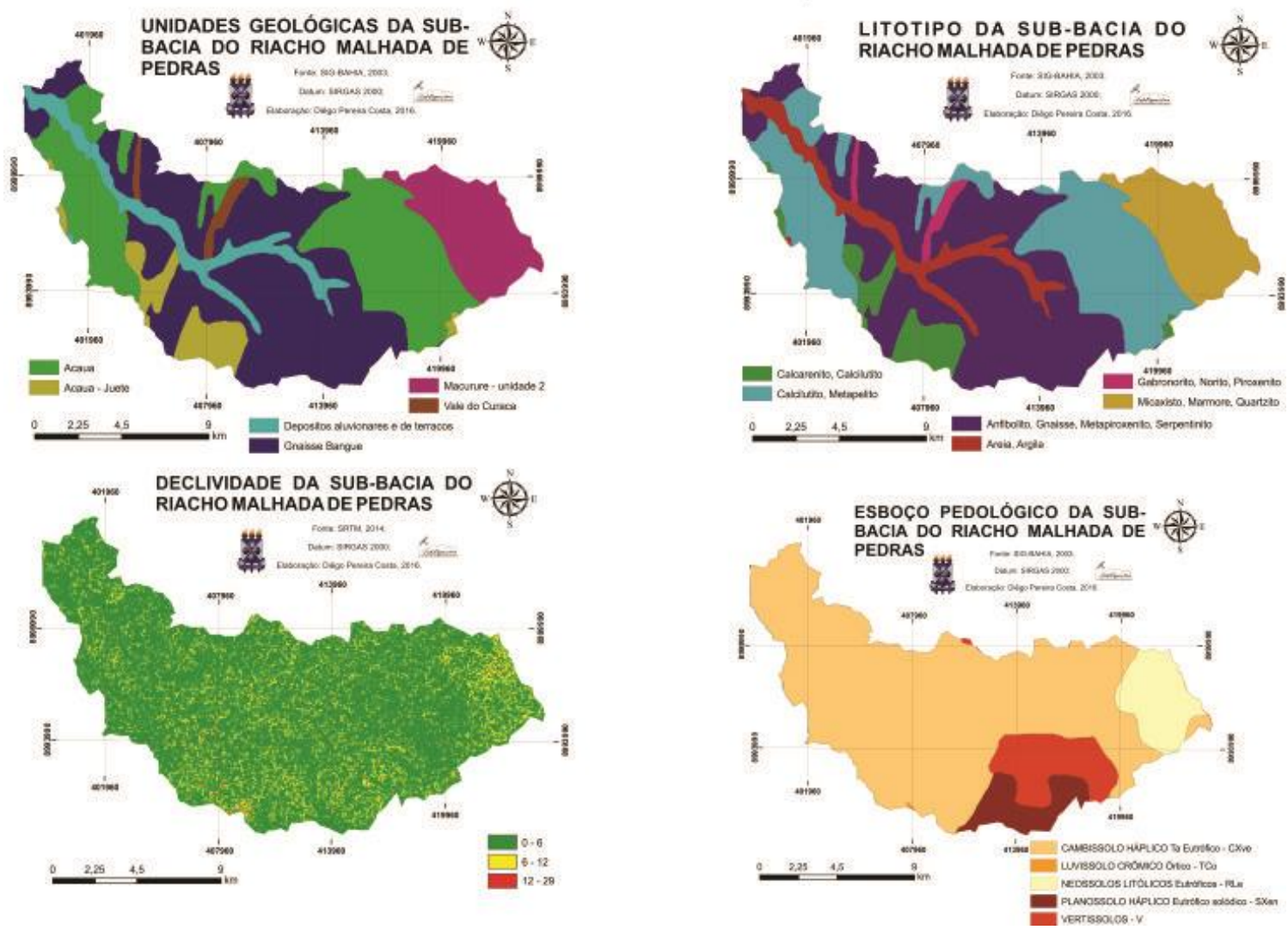

Figura 1: Esboço geoambiental da área de estudo. 


\section{BIBLIOTECA ESPECTRAL:}

De acordo com Alba (2007) a espectrorradiometria estuda os espectros derivados da interação da energia eletromagnética com os objetos radiantes, no caso a reflectância espectral, viabilizando sua utilização na identificação de minerais.

Para a medição das assinaturas espectrais, foi realizado um trabalho de campo com o objetivo de realizar medidas in-situ, como também, coletar amostras para posterior análise no laboratório.

Assim, devido as limitações de tempo geradas pelo cancelamento da bolsa, optou-se por construir um quadro com as amostras de campo e suas respectivas curvas espectrais (TABELA 1).

Tabela 1. Biblioteca espectral das amostras de rochas.

\begin{tabular}{l} 
AMOSTRA \\
\hline AFLORAMENTO \\
PIROXENITO \\
SERROTE \\
UTM W - 397.063,156 \\
UTM S - 8.968.349,062 \\
ALORAMENTO \\
BIOTITA VERMELHO \\
LESTE \\
UTM W - 397.282,795 \\
UTM S - 8.971.145,202 \\
BIOTITO OXIDADO \\
MALAQUITA \\
VERMELHO LESTE \\
UTM W 397.282,795 \\
UTM S 8.971.145,202 \\
GNAISSE ALTERADO \\
VERMELHO OESTE \\
UTM W 397.171,636 \\
UTM S 8.971.966,453 \\
\hline GNAISSE CONTATO \\
VERMELHO OESTE \\
UTM W 397.171,636 \\
UTM S 8.971.966,453 \\
GNAISSE VERMELHO \\
OESTE \\
UTM W 397.171,636 \\
UTM S 8.971.966,453 \\
UTM W 397.057,336 \\
UTM S 8.968.443,254 \\
UTM W 396.761,531 \\
OXIDAD S.970.630,304
\end{tabular}




\begin{tabular}{l} 
OXIDADO \\
SUPERFICIE \\
VERMELHO SUL \\
UTM W 396.761,531 \\
UTM S 8.970.630,304 \\
OXIDADO \\
TRINCHEIRA \\
BIOTITA VERMELHO \\
SUL \\
UTM W 396.668,397 \\
UTM S 8.970.641,946 \\
OXIDADO \\
TRINCHEIRA \\
VERMELHO SUL \\
UTM W 396.668,397 \\
UTM S 8.970.641,946 \\
\hline PIROXENITO \\
PAREDÃO \\
UTM W 397.271,649 \\
UTM S 8.964.934,872 \\
\hline PIROXENITO \\
ROLADO SERROTE \\
UTM W 397.048,098 \\
UTM S 8.968.362,372
\end{tabular}

\section{CONSIDERAÇÕES FINAIS (ou Conclusão)}

- As discussões e conclusões deste trabalho foram prejudicadas pelo cancelamento da bolsa;

- O presente estudo evidência um grande potencial para predizer questões de degradação ambiental, para identificação de minerais para exploração, como também, para logística de estudo e exploração;

- A biblioteca espectral pode auxiliar na caracterização dos depósitos existentes na área, pois apresenta picos de absorção relevantes em diversos pontos do espectro.

\section{REFERÊNCIAS}

AB'SABER, A. N. Domínios de natureza no Brasil, potencialidades paisagísticas. São Paulo: Ateliê Editorial, 2003

ALBA, J. M. F. O Uso da Espectrorradiometria no Mapeamento de Solos: Estudo de Casona Estação Experimental Terras Baixas. EMBRAPA / 1 ed. 2007. PelotasRS.

FRANCA-ROCHA, W. de J. S. Modelagem metalogenética espacial: Estudo de caso na Bacia de Irecê. Salvador: CBPM, 2015.

SILVA, A. de B. Sistemas de informacoes geo-referenciais: conceitos e fundamentos. Campinas, SP: Ed. da Unicamp, 1999. 236 p.

TEIXEIRA, J. B. G. et al. Depósitos de Cobre do Vale do Rio Curaçá, Bahia. In: BRITO, R. C.; SILVA, M. G.; KUYUMJIAN, R. M. (Ed). Modelos de depósitos de Cobre do Brasil e sua resposta ao intemperismo. Brasília: CPRM, 2010.

TORRES, C. A. Mineral Exploration Using GIS and Processed Aster Images. University of Texas at San Antonio, 2007. 